\title{
Reference range for uterine artery Doppler pulsatility index using transvaginal ultrasound at 20-24w6d of gestation in a low-risk Brazilian population
}

\author{
Alberto Borges Peixoto ${ }^{1,2}$, Taciana Mara Rodrigues Da Cunha Caldas ${ }^{1,2}$, Gabriele Tonni ${ }^{3}$, Priscilla De Almeida Morelli ${ }^{2}$, \\ Larissa D'amico Santos ${ }^{2}$, Wellington P. Martins ${ }^{4}$, Edward Araujo Júnior ${ }^{5}$ \\ ${ }^{1}$ Mario Palmério University Hospital - University of Uberaba (UNIUBE), Uberaba-MG, Brazil. \\ ${ }^{2}$ Radiologic Clinic of Uberaba (CRU), Uberaba-MG, Brazil \\ ${ }^{3}$ Department of Obstetrics and Gynecology, Prenatal Diagnostic Center, Guastalla Civil Hospital, Reggio Emilia, Italy \\ ${ }^{4}$ Department of Obstetrics and Gynecology, Ribeirão Preto Medical School, University of São Paulo (DGO-FMRP-USP), \\ Ribeirão Preto-SP, Brazil \\ ${ }^{5}$ Department of Obstetrics, Paulista School of Medicine - Federal University of São Paulo (EPM-UNIFESP), \\ São Paulo-SP, Brazil
}

\section{Abstract}

Objective: To establish reference range for uterine artery (UtA) Doppler pulsatility index (PI) using transvaginal ultrasound at 20-24w6d of gestation in a Brazilian population.

Material and Methods: A retrospective cross-sectional study in 847 low-risk pregnant women undergoing routine second trimester ultrasound examination was conducted from February 2012 through March 2015. The mean UtA PI was calculated using color Doppler ultrasound with UtA gated at the level of the internal os. Mean \pm standard deviation and ranges for UtA Doppler PI in relation to gestational age (GA) are reported. Polynomial regression was used to obtain the best fit using mean UtA Doppler PI and GA (weeks) with adjustments performed using determination coefficient $\left(\mathrm{R}^{2}\right)$. The $5^{\text {th }}, 50^{\text {th }}$, and $95^{\text {th }}$ percentiles for the mean UtA Doppler PI in relation to GA were determined.

Results: The mean UtA Doppler PI ranged from 1.14 at 20 weeks to 0.95 at 24 weeks of gestation. The best-fit curve of mean UtA Doppler PI as a function of GA was a first-degree polynomial regression: mean UtA Doppler $\mathrm{PI}=1.900-0.038 \times \mathrm{GA}\left(\mathrm{R}^{2}=0.01\right)$.

Conclusion: In summary, when the mean UtA PI Doppler values were measured by transvaginal ultrasound at 20-24w6d of gestation, decrease in UtA Doppler PI values with advancing GA was observed. Reference range for the mean UtA Doppler PI at 20-24w6d of gestation using the transvaginal ultrasound in a low-risk Brazilian population was established. We believe that this reference range may be of clinical value in daily obstetric practice. (J Turk Ger Gynecol Assoc 2016; 17: 16-20)

Keywords: Uterine Doppler artery, second trimester, reference range

Received: 05 October, 2015

Accepted: 15 January, 2016

\section{Introduction}

Preeclampsia (PE) is thought to be the consequence of inadequate trophoblastic invasion of maternal uterine vessels (1-3). A correlation between the histopathological findings and increased impedance to flow and subsequent development of PE as documented by abnormal waveform analysis and Doppler indices has been well documented and reported $(4,5)$. There is evidence that the uterine artery (UtA) Doppler ultrasound shows more accuracy for the prediction of PE when performed alone in the second than in the first trimester of pregnancy (6).
In clinical setting, reference ranges for UtA Doppler ultrasound during pregnancy are recommended for the appropriate analysis of impedance to flow. In this regard, pulsatility index (PI) has been advocated as the best Doppler index (7). Gómez et al. (7) contributed to the construction of reference range of UtA Doppler PI using transvaginal and transabdominal ultrasound. Specifically, transvaginal approach was used at 11-14 weeks of gestation, whereas transabdominal approach was used at 15-41 weeks. Ferreira et al. (8) compared the reproducibility of UtA Doppler PI in the first and second trimesters of pregnancy using both transvaginal and transabdominal scan and observed that PI was evenly significantly higher in both trimesters using transvaginal approach. 
According to Fetal Medicine Foundation (FMF) guidelines, risk assessment for premature delivery should be evaluated by cervical length measurement at 20-24 weeks of gestation using transvaginal ultrasound. At the same time, UtA Doppler PI can be measured to screen for the development of PE, fetal growth restriction (FGR), abruptio placentae, and stillbirth (9-19).

Therefore, the aim of this study was to establish the reference range for the mean UtA Doppler PI obtained using transvaginal ultrasound in a low-risk Brazilian population at 20-24w6d of gestation.

\section{Material and Methods}

A retrospective cross-sectional study in 847 low-risk pregnant women undergoing routine second trimester ultrasound examination was conducted from February 2012 through March 2015. This study was approved by the Ethic Committee of Uberaba University (CAAE: 50412115.0.0000.5145). Low-risk pregnant women were randomly selected either from public or private health services of the metropolitan region of Uberaba, Southeast Brazil.

Inclusion criteria were the following: singleton pregnancy, gestational age (GA) determined by the last menstrual period and confirmed by an ultrasound examination performed before 22 weeks of gestation (crown-rump length between 11 and $13 \mathrm{w} 6 \mathrm{~d}$ and biparietal diameter between 14 and 22w0d), and normal fetal growth (estimated fetal weight within the $10^{\text {th }}$ and the 90th percentile according to the standard curve] (20). Exclusion criteria were as follows: PE in previous pregnancy, pregestational diabetes, disease of connective tissue, renal diseases, chromosomal abnormalities, or congenital malformations detected by prenatal ultrasound. Pregnant women were assessed once, and postnatal outcomes were not available.

The sample size was calculated according to Royston's precept, which a sample of approximately 20 cases per GA is recommended to construct reference ranges for fetal biometric parameters (21).

Clinical investigation was carried out at Mário Palmério University Hospital and Radiology Clinic of Uberaba. Ultrasound examinations were performed using by two examiners (ABP and TMRCC) with FMF accreditation by means of transvaginal ultrasound. The ultrasound exams were performed using only transvaginal route in two apparatus (Accuvix V20-Samsung; Seoul, Korea and Voluson E6-General Electric; Zipf, Austria) equipped with endovaginal probes.

UtA Doppler PI was assessed by transvaginal approach according to the following steps: (i) pregnant women were required to empty their bladder and were positioned in the classical dorsal lithotomy position and (ii) a sagittal view of the uterine cervix was obtained. The probe was sweep laterally until the visualization of paracervical vessels. Color Doppler was activated to identify the UtA at the level of the internal os. UtA was gated at this point just before branching into arcuate arteries. Care has been taken not to insonate the cervicovaginal artery (which runs from cephalad to caudad) or the arcuate arteries. Velocities over $50 \mathrm{~cm} / \mathrm{s}$ are typical of uterine arteries, which can be used to differentiate this vessel from arcuate arteries (22). Routinely in our center, after angle correction $\left(<30^{\circ}\right)$ when necessary, pulsed Doppler gate was placed over the whole width of the vessel to calculate PI and peak systolic velocity of UtA. When at least three similar consecutive waveforms were obtained, mean PI value of the left and right uterine arteries was calculated (7) (Figure 1).

Data were transferred to an Excel spread sheet (Microsoft Corp.; Redmond, WA, USA) and analyzed by one of the authors (WPM) using PASW program version 18.0 (SPSS Inc.; Chicago, IL, USA) and GraphPad version 5.0 (GraphPad Software; San Diego, CA, USA). Maternal demographic characteristics such as age, height, weight, body mass index (BMI), number of pregnancies, and parity were reported as mean and ranges. Ethnicity, cigarette smoking, and alcohol consumption were reported as percentage. To obtain reference values for mean UtA Doppler PI, a polynomial regression model, as recommended by Altman et al. (23) was used. Regression analysis to obtain the best-fit model polynomial equation for the measurements and their respective standard deviation (SD) values depending on the GA was calculated. Percentiles measurements were calculated

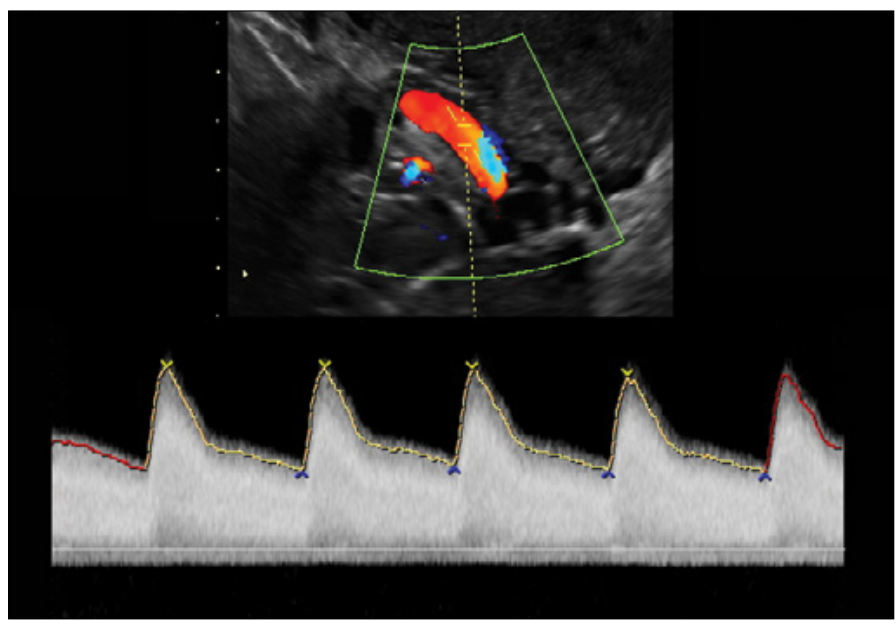

Figure 1. Transvaginal ultrasound showing the uterine artery Doppler The uterine artery is identified by color Doppler flow mapping and Doppler velocity waveforms. When three similar consecutive waveforms were obtained, the automatic mean pulsatility index (PI) of the left and right uterine arteries was measured, and mean PI Doppler was calculated.

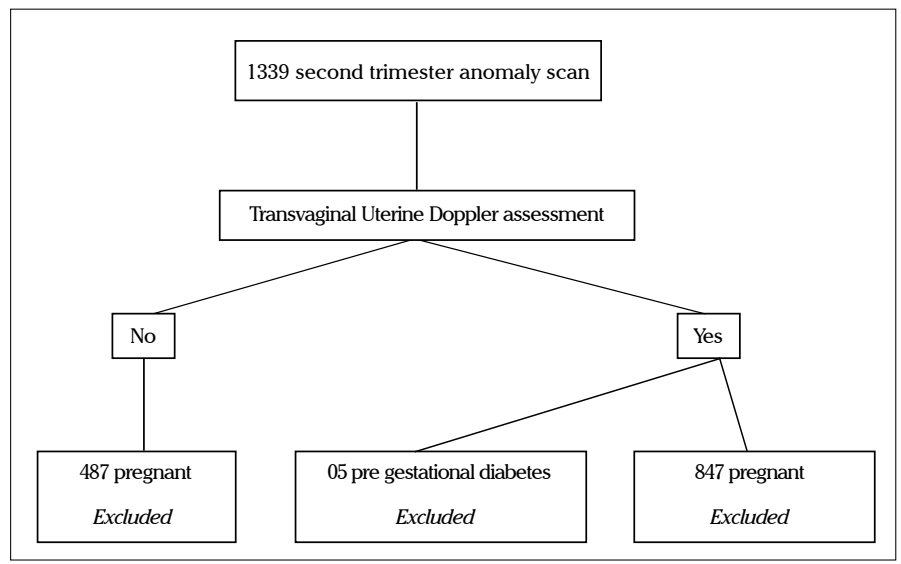

Figure 2. Flow diagram showing patient assessment process 
using the following formula: $=$ mean $+(\mathrm{SD} \times \mathrm{K})$, where $\mathrm{K}$ is the corresponding percentile of the standard normal distribution: \pm 1.65 for the $5^{\text {th }}$ and $95^{\text {th }}$ percentile. The $5^{\text {th }}, 50^{\text {th }}$, and $95^{\text {th }}$ percentiles were determined for each GA (23).

\section{Results}

Initially, 1339 pregnant women were selected; however, 492 (36.8\%) were excluded because not met the inclusion criteria: five $(0.4 \%)$ with pregestational diabetes and 487 (36.4\%) have declined transvaginal uterine Doppler assessment. This left 847 pregnant women for final statistical analysis (Figure 2). The distribution of pregnant women in each GA period (weeks) was the following: $20-20 w+6 d(72) ; 21-21 w+6 d(204) ; 22-22 w 6 d$ (384); 23-23w6d (16), and 24-24w6d (41).

The demographic characteristics of study population are shown in Table 1.

The relationship between mean UtA Doppler PI and GA (weeks) was described by a first-degree polynomial regression by the following formula: mean UtA Doppler $\mathrm{PI}=1.900-0.038 \times \mathrm{GA}$ $\left(\mathrm{R}^{2}=0.01\right)$. Figure 3 shows the scatterplot of mean UtA Doppler PI as a function of GA (weeks). Table 2 shows the 5th, 50th, and 95th percentiles of mean UtA Doppler PI as a function of GA, from 20 to $24 w 6 \mathrm{~d}$ of gestation.

\section{Discussion}

This study has established reference ranges for the mean UtA Doppler PI in a low-risk Brazilian pregnant women using transvaginal ultrasound from 20 to $24 w 6 \mathrm{~d}$ of gestation.

In a study by Kurdi et al. (16) in 946 women with known outcome measures (PE, birth weight, abruptio placentae, and stillbirth), the presence of bilateral notches at UtA Doppler investigation was associated with an odds ratio (OR) of 12.8 for developing early $\mathrm{PE}$ and an OR of 52.6 for PE requiring delivery before 37 weeks of gestation. Opposite, pregnant women with normal UtA Doppler studies had an OR for developing PE of 0.11 (95\% confidence interval $0.04-0.28$ ) and 0.3 for delivery of small for gestational age newborns $<5^{\text {th }}$ centile. In addition, this study demonstrated that in pregnant women with bilateral notches and mean resistance index (RI) of $>0.55$, the positive predictive value for the main outcome measures was $46 \%$. Persistence of a diastolic notch (around 24 weeks of gestation) or abnormal flow velocity ratio has been associated with inadequate trophoblast invasion (24).

Cnossen et al. (6), reviewing data regarding 79547 pregnant women with PE and 41131 fetuses with FGR, reported that UtA Doppler ultrasound showed a more accurate prediction when performed in the second than in the first trimester of pregnancy and that an increased PI with notching was the best predictor of PE. Moreover, an increased PI with notching was also the best predictor of overall and severe FGR among low-risk patients. The authors concluded that abnormal UtA waveforms are a better predictor of PE than FGR. PI and RI have been the most commonly used indices; however, large studies on UtA Doppler waveforms during pregnancy have uniformly used PI $(13,17,18)$.
Cervical length measurements performed by transvaginal ultrasound at the time of routine second trimester are a recommended method of screening for increased risk of early preterm birth ( $<32$ weeks of gestation). Thus, we evaluated the distribution of UtA Doppler PI measurements using transvaginal ultrasound rather than RI and/or transabdominal approach. PI showed better the velocity waveform, which includes the area below the curve in the formula. Thereat, PI gives detailed

Table 1. Demographic characteristics of study population

\begin{tabular}{|l|c|c|c|}
\hline & Mean & Min-Max & Percentage \\
\hline Age (years) & 30.6 & $16.6-44.1$ & \\
\hline Height (cm) & 168 & $145-187$ & \\
\hline Weight (kg) & 76 & $43-146.2$ & \\
\hline BMI (kg/m²) & 28.2 & $16.3-57.1$ & \\
\hline Number of pregnancies & 2 & $1-5$ & \\
\hline Parity & 1 & $0-4$ & \\
\hline Gestational age (weeks) & 22.9 & $20-24.9$ & \\
\hline Ethnicity & & & 82.6 (white) \\
\hline Smoker & & & 1.4 \\
\hline Alcohol consumption & & & 2.8 \\
\hline BMI: body mass index & & & \\
\hline
\end{tabular}

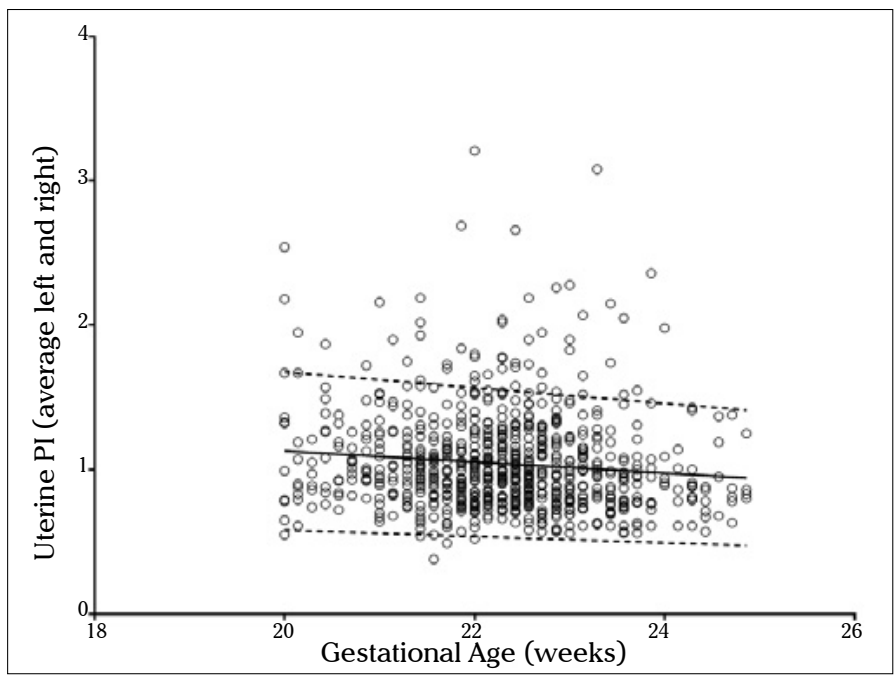

Figure 3. Scatterplot of the mean uterine artery Doppler as function of gestational age (weeks)

Table 2. Estimated $5^{\text {th }}, \mathbf{5 0 ^ { \text { th } }}$, and $95^{\text {th }}$ percentiles for the mean uterine artery pulsatility index according to gestational age

\begin{tabular}{|l|c|c|c|}
\hline GA (weeks) & $\mathbf{5}^{\text {th }}$ & $\mathbf{5 0}^{\text {th }}$ & $\mathbf{9 5}^{\text {th }}$ \\
\hline 20 & 0.58 & 1.14 & 1.68 \\
\hline 21 & 0.56 & 1.10 & 1.62 \\
\hline 22 & 0.54 & 1.06 & 1.57 \\
\hline 23 & 0.52 & 1.03 & 1.51 \\
\hline 24 & 0.49 & 0.99 & 1.46 \\
\hline GA: gestational age & & \\
\hline
\end{tabular}


information about the presence or absence of a protodiastolic notch (7).

Gómez et al. (7), using transvaginal and transabdominal ultrasound examinations from 11 to 41 weeks of gestation, demonstrated a significant decrease in the mean UtA Doppler PI between 11 and 34 weeks, whereas a stable plateau was seen until 41 weeks. Our observation of a significant decrease in the mean UtA Doppler PI from 20 to $24 \mathrm{w} 6 \mathrm{~d}$ of gestation is in agreement with that reported by Gómez et al. (7), although UtA Doppler PI was transabdominally evaluated in this study (1.10$0.89)$. The same findings (1.14-0.95) have been confirmed by Ferreira et al. (8) and by our results. Furthermore, our study also confirms previous reports $(6,25-27)$ indicating that the mean UtA Doppler PI has a significant and progressive decline with advancing GA.

Takahashi et al. (28) have established reference range of mean PI UtA Doppler PI between 16 and 23 weeks of gestation in 1266 singleton Japanese pregnant women. The best-fit curve was a logarithmic one that represented the relationship between mean UtA Doppler PI and GA: $\log _{10}$ mean $\mathrm{PI}=-0.0211 \times \mathrm{GA}+0.438$. Similarly, Bahlmann et al. (29) have determined reference values for blood flow velocity of UtA between 18 and 42 weeks of gestation in 921 singleton low-risk Germany pregnant women. In this study, the reference curve of the mean UtA Doppler PI was characterized by a linear pattern, showing a decrease from 0.89 to 0.65 from 18 through 42 weeks of gestation.

Reference ranges for UtA PI were established using the transabdominal route in other studies $(6,30,31)$. Gómez et al. (7) assessed 620 pregnant women in a Spain population, Medina Castro et al. (31) assessed 2081 women in a Mexico population, and Jamal et al. (30) assessed 435 women in an Iran population. The means UtA PI of our study were similar to these studies performed in different ethnic population. Although our study assessed the UtA Doppler by transvaginal route, we believe that our results may be generalized for other ethnic populations.

Few limitations are underlined as follows: (1) this was a crosssectional, retrospective study, and the postnatal outcomes were not available; pregnant women with BMI $>35 \mathrm{~kg} / \mathrm{m}^{2}$ were not excluded, and two different apparatuses were used to perform the ultrasound scans. Nonetheless, cases with PE and FGR (known conditions with elevated midtrimester UtA Doppler PI) are potentially part of the studied population. Intra- and interobserver reproducibility tests were not performed because all ultrasound examinations were carried out only two examiners with full registration by the FMF. In a recent study assessing the intra- and interobserver reproducibility of transabdominal and transvaginal ultrasound in first and second trimesters, both techniques have demonstrated similar reproducibility in the assessing of UtA Doppler PI (8). In addition, when the mean UtA PI Doppler values was measured by transvaginal ultrasound at 20-24w6d of gestation, decrease in UtA Doppler PI values with advancing GA was observed. Moreover, evaluation of UtA Doppler PI can be achieved at the same time when cervical length assessment is carried out to estimate the risk of premature delivery during second trimester scan.
In summary, UtA Doppler PI decreases with advancing GA when the mean UtA Doppler PI is measured at 20-24w6d of gestation by means of transvaginal ultrasound. Finally, reference range for the mean UtA Doppler PI at 20-24w6d of gestation using the transvaginal ultrasound in a low-risk Brazilian population was established. We believe that this reference range may be of clinical value in daily obstetric practice.

Ethics Committee Approval: Ethics committee approval was received for this study from the Local Ethics committee of University of Uberaba (UNIUBE) (CAAE: 50412115.0.0000.5145).

Informed Consent: Consent form was not necessary, because it was a retrospective study.

Peer-review: Externally peer-reviewed.

Author Contributions: Concept - E.A.J., W.P.M.; Design - A.B.P., W.P.M.; Supervision - E.A.J.; Materials - P.A.M., A.B.P.; Data Collection and/or Processing - A.B.J., T.M.R.C.C. P.A.M.; Analysis and/or Interpretation - W.P.M.; Literature Review - E.A.J., G.T.; Writer - E.A.J., G.T.; Critical Review - G.T.

Conflict of Interest: No conflict of interest was declared by the authors.

Financial Disclosure: The authors declared that this study has received no financial support.

\section{References}

1. Khong T, De Wolf F, Robertson WB, Brosens I. Inadequate maternal vascular response to placentation in pregnancies complicated by pre-eclampsia and by small for gestational age infants. Br J Obstet Gynaecol 1986; 93: 1049-59. [CrossRef]

2. Meekins JW, Pijnenborg R, Hanssens M, McFayden IR, Van Asshe A. A study of placental bed spiral arteries and trophoblasticinvasion in normal and severe pre-eclamptic pregnancies. Br J Obstet Gynaecol 1994; 101: 669-74. [CrossRef]

3. Olofsson P, Laurini RN, Marsal K. A high uterine artery pulsatility index reflects a defective development of placental spiral arteries in pregnancies complicated by hypertension andfetal growth retardation. Eur J Obstet Gynecol 1993; 49: 161-8. [CrossRef]

4. Campbell S, Diaz-Recasens J, Griffin DR, Cohen-Overbeek TE, Pearce JM, Willson K, et al. New Doppler technique for assessing utero-placental blood flow. Lancet 1983; 1: 675-7. [CrossRef]

5. Fleischer A, Schulman H, Farmakides G, Bracero L, Grunfeld L, Rochelson B, et al. Uterine artery Doppler velocimetry in pregnant women with hypertension. Am J Obstet Gynecol 1986; 154: 806-13. [CrossRef]

6. Cnossen JS, Morris RK, ter Riet G, Mol BW, van der Post JA, Coomarasamy A, et al. Use of uterine artery Doppler ultrasonography to predict pre-eclampsia and intrauterine growth restriction: a systematic review and bivariable meta-analysis. CMAJ 2008; 178: 701-8. [CrossRef]

7. Gómez O, Figueras F, Fernández S, Bennasar M, Martínez JM, Puerto B, et al. Reference ranges for uterine artery mean pulsatility index at 11-41 weeks of gestation. Ultrasound Obstet Gynecol 2008; 32: 128-32. [CrossRef]

8. Ferreira AE, Mauad Filho F, Abreu PS, Mauad FM, Araujo Junior E, Martins WP. The reproducibility of first and second trimester uterine artery pulsatility index by transvaginal and transabdominal ultrasound. Ultrasound Obstet Gynecol 2015; 46: 546-52. [CrossRef] 
9. Jurkovic D, Jauniaux E, Kurjak A, Hustin J, Campbell S, Nicolaides $\mathrm{KH}$. Transvaginal color Doppler assessment of the uteroplacental circulation in early pregnancy. Obstet Gynecol 1991; 77: 365-9.

10. Van den Elzen HJ, Cohen-Overbeek TE, Grobbee DE, Quartero RW, Wladimiroff JW. Early uterine artery Doppler velocimetry and the outcome of pregnancy in women aged 35 years and older. Ultrasound Obstet Gynecol 1995; 5: 328-33. [CrossRef]

11. Harrington K, Goldfrad C, Carpenter RG, Campbell S. Transvaginal uterine and umbilical artery Doppler examination of 12-16 weeks and the subsequent development of pre-eclampsia and intrauterine growth retardation. Ultrasound Obstet Gynecol 1997; 9: 94-100. [CrossRef]

12. Harrington K, Carpenter RG, Goldfrad C, Campbell S. Transvaginal Doppler ultrasound of the uteroplacental circulation in the early prediction of pre-eclampsia and intrauterine growth retardation. Br J Obstet Gynaecol 1997; 104: 674-81. [CrossRef]

13. Martin AM, Bindra R, Curcio P, Cicero S, Nicolaides KH. Screening for pre-eclampsia and fetal growth restriction by uterine artery Doppler at 11-14 weeks of gestation. Ultrasound Obstet Gynecol 2001; 18: 583-6. [CrossRef]

14. Gómez O, Martínez JM, Figueras F, Del Río M, Borobio V, Puerto B, et al. Uterine artery Doppler at 11-14 weeks of gestation to screen for hypertensive disorders and associated complications in an unselected population. Ultrasound Obstet Gynecol 2005; 26:490-4. [CrossRef]

15. Harrington K, Cooper D, Lees C, Hecher K, Campbell S. Doppler ultrasound of the uterine arteries: the importance of bilateral notching in the prediction of pre-eclampsia, placental abruption or delivery of a small-for-gestational-age baby. Ultrasound Obstet Gynecol 1996; 7: 182-8. [CrossRef]

16. Kurdi W, Campbell S, Aquilina J, England P, Harrington K. The role of color Doppler imaging of the uterine arteries at 20 weeks' gestation in stratifying antenatal care. Ultrasound Obstet Gynecol 1998; 12: 339-45. [CrossRef]

17. Albaiges G, Missfelder-Lobos H, Lees C, Parra M, Nicolaides KH. One-stage screening for pregnancy complications by color Doppler assessment of the uterine arteries at 23 weeks' gestation. Obstet Gynecol 2000; 96: 559-64. [CrossRef]

18. Papageorghiou AT, Yu CK, Bindra R, Pandis G, Nicolaides KH. Multicenter screening for pre-eclampsia and fetal growth restriction by transvaginal uterine artery Doppler at 23 weeks of gestation. Ultrasound Obstet Gynecol 2001; 18: 441-9. [CrossRef]

19. Becker R, Vonk R, Vollert W, Entezami M. Doppler sonography of uterine arteries at 20-23 weeks: risk assessment of adverse pregnancy outcome by quantification of impedance and notch. $\mathrm{J}$ Perinat Med 2002; 30: 388-94. [CrossRef]
20. Yudkin PL, Aboualfa M, Eyre JA, Redman CW, Wilkinson AR. New birthweight and head circumference centiles for gestational ages 24 to 42 weeks. Early Hum Dev 1987; 15: 45-52. [CrossRef]

21. Royston P, Wright EM. How to construct 'normal ranges' for fetal variables. Ultrasound Obstet Gynecol 1998; 11: 30-8. [CrossRef]

22. Bhide A, Acharya G, Bilardo CM, Brezinka C, Cafici D, HernandezAndrade E, et al. ISUOG Practice Guidelines: use of Doppler ultrasonography in obstetrics. Ultrasound Obstet Gynecol 2013; 41: 233-9. [CrossRef]

23. Altman DG, Chitty LS. Charts of fetal size I: Methodology. Br J Obstet Gynaecol 1994; 101: 29-34. [CrossRef]

24. Bolte AC, Dekker GA. Uterine artery Doppler as screening tool for preeclampsia. In: Wildschut HJ, Weiner CP (eds). When to screen in obstetrics and gynecology. Philadelphia: Saunders Elsevier; 2006. p. 408-19. [CrossRef]

25. Murakoshi T, Sekizuka N, Takakuwa K, Yoshizawa H, Tanaka K. Uterine and spiral artery flow velocity waveforms in pregnancyinduced hypertension and/or intrauterine growth retardation. Ultrasound Obstet Gynecol 1996; 7: 122-8. [CrossRef]

26. Bower S, Vyas S, Campbell S, Nicolaides KH. Color Doppler imaging of the uterine artery in pregnancy: normal ranges of impedance to blood flow, mean velocity and volume of flow. Ultrasound Obstet Gynecol 1992; 2: 261-5. [CrossRef]

27. Kurmanavicius J, Florio I, Wisser J, Hebisch G, Zimmermann R, Müller R, et al. Reference resistance indices of the umbilical, fetal middle cerebral and uterine arteries at 24-42 weeks of gestation. Ultrasound Obstet Gynecol 1997; 10: 112-20. [CrossRef]

28. Takahashi K, Ohkuchi A, Hirashima C, Matsubara S, Suzuki M. Establishing reference values for mean notch depth index, pulsatility index and resistance index in the uterine artery at 16-23 weeks' gestation. J Obstet Gynaecol Res 2012; 38: 1275-85. [CrossRef]

29. Bahlmann F, Fittschen M, Reinhard I, Wellek S, Steiner E. Reference values for blood flow velocity in the uterine artery in normal pregnancies from 18 weeks to 42 weeks of gestation calculated by automatic Doppler waveform analysis. Ultraschall Med 2012; 33: 258-64. [CrossRef]

30. Jamal A, Abbasalizadeh F, Vafaei H, Marsoosi V, Eslamian L. Multicenter screening for adverse pregnancy outcomes by uterine artery Doppler in the second and third trimester of pregnancy. Med Ultrason 2013; 15: 95-100. [CrossRef]

31. Medina Castro N, Figueroa Diesel H, Gúzman-Huerta M, HernándesAndrades E. [Normal reference values of the pulsatility index from the uterine and umbilical arteries during pregnancy]. Ginecol Obstet Mex 2006; 74: 509-15. 